\title{
TAMANHO ÓTIMO DA PARCELA EXPERIMENTAL DE ABACAXIZEIRO 'VITÓRIA'1
}

\author{
FRANCISCO DE ASSIS PEREIRA LEONARDO², WALTER ESFRAIN PEREIRA³ \\ SILVANDA DE MELO SILVA ${ }^{4}$, RAUNIRA DA COSTA ARAÚJO5, \\ REJANE MARIA NUNES MENDONÇA ${ }^{6}$
}

RESUMO - No planejamento experimental, a parcela experimental é um fator determinante para o sucesso da pesquisa. Portanto, é necessário que o pesquisador defina adequadamente a constituição da parcela ou unidade experimental, no intuito de aumentar a eficiência do experimento e diminuir o erro experimental. Em decorrência da grande variabilidade no tamanho da parcela encontrada nos experimentos com abacaxizeiro, realizou-se uma pesquisa objetivando estimar o tamanho ótimo para parcelas experimentais, considerando diferentes características. Os dados utilizados para este trabalho foram coletados em 100 plantas de abacaxizeiro 'Vitória'. Foram coletados 100 frutos e 100 folhas "D" de plantas cultivadas na mesma área experimental e submetidas às mesmas práticas de cultivo. Foram avaliados nos frutos: o comprimento, o diâmetro e a massa. Na folha "D”, foram avaliados o comprimento e a massa, além dos teores de N, P e K. As estimativas do tamanho da parcela foram baseadas nos métodos do modelo linear de resposta a platô e da curvatura máxima. O tamanho ótimo da parcela para a avaliação do abacaxizeiro 'Vitória' é de 15 a 20 unidades experimentais por parcela, para as características dos frutos e das folhas, pelo método do modelo linear de resposta a platô. Para a avaliação dos teores de N, P e K, 10 folhas representam o tamanho ótimo da parcela pelo método do modelo linear de resposta a platô. Por outro lado, o tamanho ótimo da parcela para avaliação dos frutos e das folhas do abacaxi 'Vitória' é de 1,7 a 2,8 unidades experimentais pelo método da curvatura máxima. Enquanto, para os teores de N, P e K, 3 a 5 unidades experimentais representam o tamanho ótimo da parcela pelo método da curvatura máxima.

Termos de indexação: Ananas comosus var. comosus, frutos, unidade experimental.

\section{OPTIMUM SIZE OF THE EXPERIMENTAL PLOT OF PINEAPPLE 'VICTORY'}

\begin{abstract}
In the experimental design the plot is a determining factor for the success of the research. Therefore, it is necessary that the researcher adequately define the constitution of the plot or experimental unit, in order to increase the efficiency of the experiment and reduce experimental error. Due to the great variability in the plot size found in experiments with pineapple, a research was carried out to estimate the optimal size for plots considering different characteristics. The data used for this chapter were collected in 100 pineapple "Vitória'. It was collected 100 fruits and 100 "D” leaves of plants grown in the same experimental area and subject to the same farming practices. It was evaluated in the fruits: length, diameter and weight. In the ' $\mathrm{D}$ ' leaves it was measured the length and weight, and concentration of $\mathrm{N}, \mathrm{P}$ and $\mathrm{K}$. Estimates of plot size were based on the methods of linear response plateau and maximum curvature. The plot size for evaluation of pineapple 'Vitória' is 15-20 units per plot for the characteristics of the fruits and leaves by the method of linear model response plateau. To evaluate the concentrations of $\mathrm{N}, \mathrm{P}$ and $\mathrm{K}, 10$ leaves represent the optimum plot size by linear response plateau model. On the other hand, the plot size for evaluation of the fruit and leaves of the cultivar Vitória is from 1.7 to 2.8 units by the method of maximum curvature. While for the N, P and K, 3-5 units represent the experimental plot size by the method of maximum curvature. Index terms: Ananas comosus var. comosus, fruits, experimental unit.
\end{abstract}

\footnotetext{
${ }^{1}$ (Trabalho 396-13). Recebido em: 15-10-2013. Aceito para publicação em: 28-07-2014.

${ }^{2}$ Doutor em Agronomia, Programa de Pós-Graduação em Agronomia CCA-UFPB. Câmpus II, Areia-PB. E-mail:fap_leonardo@ hotmail.com

${ }^{3}$ Professor Dr. Associado do DCFS-CCA-UFPB; Bolsista de Produtividade do CNPq. Câmpus II, Areia-PB. E-mail: walterufpb@ yahoo.com.br.

${ }^{4}$ Professora Dra. Associada do DCFS-CCA-UFPB; Bolsista de Produtividade do CNPq. Câmpus II, Areia-PB. E-mail:silvasil@cca. ufpb.br

${ }^{5}$ Professora Dra. Associada do CCHSA-UFPB; Câmpus III, Bananeiras-PB. E-mail: raunira@cchsa.ufpb.br

${ }^{6}$ Professora Dra. Associada do DFCA-CCA-UFPB; Câmpus II, Areia-PB. E-mail:rejane@cca.ufpb.br
} 


\section{INTRODUÇ̃̃O}

No planejamento experimental, a parcela experimental é um fator determinante para o sucesso da pesquisa, portanto é necessário que o pesquisador defina adequadamente a constituição da parcela ou da unidade experimental, no intuito de aumentar a eficiência do experimento e diminuir o erro experimental. Embora seja considerado que quanto maior o tamanho da parcela menor o erro experimental, essa relação não é linear (PARANAÍBA et al., 2009a).

Aadoção de um tamanho de parcela adequado é uma das maneiras de reduzir o erro experimental. Esse tamanho ótimo da parcela é muitas vezes recomendado por meio de estudos empíricos feitos para uma região ou cultura específica. Porém, do ponto de vista estatístico, essa prática não é a melhor, já que o tamanho ótimo da parcela depende da heterogeneidade do local experimental (CARGNELUTTI FILHO et al., 2011). O tamanho das parcelas não pode ser generalizado, pois variam com o solo e com a cultura.

Entre os métodos para a estimação do tamanho ótimo de parcela, destacam-se dois métodos recentes: o método linear em resposta a platô e o método da curvatura máxima do modelo do coeficiente de variação (CARGNELUTTI FILHO et al., 2011).

A teoria dos modelos lineares segmentados com platô foi aplicada no contexto de dimensionamento de tamanho ótimo de parcela. Para isso, adotou-se o seguinte modelo:

$$
\mathrm{CV}_{(\mathrm{x})}= \begin{cases}\beta_{0}+\beta_{1} \mathrm{x}+\varepsilon_{\mathrm{x}} & \text { se } \mathrm{x} \leq \mathrm{x}_{0} \\ \operatorname{CVP}+\varepsilon_{\mathrm{x}} & \text { se } \mathrm{x} \leq \mathrm{x}_{0}\end{cases}
$$

Em que: $\mathrm{CV}_{(\mathrm{x})}$ é o coeficiente de variação entre totais de parcelas com $\mathrm{x}$ unidades experimentais básicas; $\mathrm{X}_{0}$ é o tamanho ótimo de parcelas para o qual o modelo linear se transforma em um platô, em relação à abscissa; CVP é o coeficiente de variação no ponto correspondente ao platô (junção de segmento linear e platô); $\beta_{0}$ e $\beta_{1}$ são intercepto e coeficiente angular, respectivamente, do segmento linear, e $\varepsilon_{\mathrm{x}}$ é o erro associado ao $\mathrm{CV}_{(\mathrm{x})}$ (PARANAÍBA et al., 2009a).

$\mathrm{O}$ método da curvatura máxima é um dos mais utilizados para determinar o tamanho das unidades experimentais básicas. Foi desenvolvido por Lessman e Atkins (1963), que estabeleceram uma função do tipo $\mathrm{CV}(\mathrm{x})=\frac{A}{X^{B}}$ para explicar a relação entre coeficientes de variação e tamanho da parcela, permitindo que o ponto que corresponde ao tamanho ótimo de parcela fosse determinado algebricamente.

Para abacaxizeiro, foram realizadas pesquisas com parcelas de tamanhos variáveis. Por exemplo, Silva et al. (2012), com abacaxi 'Vitória', utilizaram 20 plantas úteis por parcela; por sua vez, Rodrigues et al. (2013), com a cultivar Pérola, utilizaram uma parcela útil de 64 plantas. Entretanto, Coelho et al. (2007) utilizaram uma parcela de cinco plantas para o abacaxi 'Jupi'. Contudo, pesquisas que definem o tamanho ótimo da parcela para abacaxi são inexistentes na literatura. Quanto à cultivar Vitória, destaca-se por apresentar, além de resistência à fusariose, ausência de espinhos nas folhas, bom crescimento e produtividade, e frutos com aptidão para consumo in natura e para industrialização (VENTURA et al., 2009).

Em decorrência da grande variabilidade no tamanho da parcela encontrada nos experimentos com abacaxizeiro, realizou-se uma pesquisa objetivando estimar o tamanho ótimo das parcelas experimentais do abacaxizeiro 'Vitória'.

\section{MATERIAL E MÉTODOS}

Os dados utilizados para o experimento foram coletados em 100 plantas de abacaxizeiro 'Vitória', na Fazenda Quandu-Itapororoca, a aproximadamente $12 \mathrm{~km}$ da sede do município de Itapororoca, Paraíba. De acordo com a classificação de Köppen, prevalece na região o clima As', quente e úmido, com chuvas de outono-inverno, período de estiagem de cinco a seis meses, temperaturas médias variando entre 22 e 26 ${ }^{\circ} \mathrm{C}$ e precipitação pluviométrica anual de $1.500 \mathrm{~mm}$.

O plantio foi realizado em fevereiro de 2010 , com mudas de abacaxizeiro 'Vitória', produzidas por cultivo in vitro. O preparo do solo constou da limpeza da área, gradagem e incorporação dos restos culturais do ciclo anterior. As mudas foram plantadas em leirões, no sistema de fileiras duplas, no espaçamento de $0,9 \times 0,40 \times 0,40 \mathrm{~m}$, resultando numa densidade de 38.400 plantas ha-1. $^{-1}$.

A adubação das plantas constou de $154 \mathrm{~kg}$ de $\mathrm{P}_{2} \mathrm{O}_{5}$ ha $^{-1}$ na adubação de plantio. Na adubação de cobertura, foram aplicados $20 \mathrm{~g}_{\text {planta }}{ }^{-1}$ da fórmula 15-00-30, em três vezes durante o ciclo, sendo a primeira aos 30 dias, a segunda aos 6 meses e a terceira aos 12 meses após o plantio.

$\mathrm{Na}$ condução do experimento, foram realizadas as práticas culturais usuais para a cultura, visando a garantir boas condições de limpeza e de sanidade das plantas (OLIVEIRA et al., 2002). O controle de plantas daninhas foi efetuado com o uso do herbicida Diuron, em pós-emergência. A irrigação foi feita nos períodos de ausência de 
precipitação pelo método de aspersão convencional, e o controle fitossanitário será feito quando necessário; entretanto, a variedade apresenta poucos problemas com enfermidades. A emissão do pedúnculo floral ocorreu naturalmente.

Para a pesquisa do tamanho da parcela, foram coletados 100 frutos e 100 folhas "D" de plantas cultivadas na mesma área experimental e submetidas às mesmas práticas de cultivo. Foram avaliados nos frutos, o comprimento, o diâmetro e a massa dos frutos. Na folha " $D$ ", foram avaliados o comprimento e a massa da folha. Para os teores foliares dos macronutrientes $\mathrm{N}, \mathrm{P} \mathrm{e} \mathrm{K}$, foram utilizadas 50 folhas. Os dados foram coletados aos 23 meses após o plantio, no mês de dezembro de 2011.

Mediante a utilização de bootstrapping (MAMMEN; SANDI, 2012), foram realizadas 1.000 simulações de amostras constituídas por 2 a 100 indivíduos, que foram utilizados para o cálculo do coeficiente de variação em função do tamanho da parcela. Estes dados foram utilizados para estimar os parâmetros dos modelos linear em resposta a platô e da curvatura máxima. Foi utilizado o software SAS 9.3 (SAS, 2011).

No método linear de resposta a platô, o tamanho ótimo da parcela é o valor onde o modelo linear se transforma em um platô, em relação à abscissa.

No método da curvatura máxima, o tamanho ótimo foi determinado algebricamente através da substituição dos parâmetros A e B na seguinte expressão:

$$
\left(\frac{A^{2} B^{2}(2 B+1)}{B+2}\right)^{\frac{1}{2+2 B}}
$$

\section{RESULTADOS}

O coeficiente de variação diminui à medida que o tamanho da parcela aumenta, estabilizando-se em 17,5 unidades experimentais básicas, indicando o ponto de estabilização do coeficiente de variação e caracterizando a parcela ótima para a avaliação da massa da infrutescência de abacaxizeiro 'Vítória' (Figura 1A).

Utilizando-se do método da curvatura máxima, obteve-se coeficiente de determinação de 92,3\%, indicando um bom ajuste dos dados à equação. Com base nos parâmetros $\mathrm{A}$ e $\mathrm{B}$ da equação, obteve-se a curvatura máxima estimada de 2,5 unidades experimentais básicas para a massa da infrutescência do abacaxi 'Vitória', representando o tamanho ótimo estimado da parcela (Figura 1B).

$\mathrm{O}$ valor estimado de tamanho ótimo da parcela pelo modelo linear de platô foi de 16,4 UEBs, ou seja, parcelas em torno de 16 frutos são adequadas para determinar o comprimento da infrutescência do abacaxi 'Vitória' (Figura 1C). O coeficiente de determinação foi de $81 \%$, indicando que houve ajuste dos dados à equação.

Observa-se, na Figura 1D, que houve ajuste da equação descrita no gráfico aos dados de comprimento da infrutescência, apresentando coeficiente de determinação de $99 \%$, o que mostra um bom ajuste. Através da equação descrita para a determinação do tamanho ótimo pelo método da curvatura máxima, obteve-se um valor de 1,7 unidade experimental básica para se avaliar o comprimento da infrutescência do abacaxi 'Vitória'.

Para a avaliação do diâmetro de infrutescências do abacaxizeiro 'Vitória', houve ajuste ao modelo linear em resposta a platô, apresentando um coeficiente de determinação de $84 \%$. O tamanho da parcela ótimo estimado pela equação de platô foi de 18,5 UEBs, com um coeficiente de variação de $7,4 \%$, indicando que parcelas em torno de 18 frutos são adequadas para determinar o diâmetro da infrutescência de abacaxizeiro 'Vitória' (Figura 1E).

De acordo com a Figura 1F, o tamanho ótimo da parcela para o diâmetro da infrutescência foi de 1,4 unidade básica experimental, obtido através da substituição dos valores de A e B na equação descrita na metodologia. Houve bom ajuste dos dados à equação descrita no gráfico, com coeficiente de determinação de 90,8\%.

Para a determinação do comprimento da folha $\mathrm{D}$, houve ajuste ao modelo de platô, com coeficiente de determinação de $85 \%$. O tamanho ótimo da parcela estimado foi de 17,6 UEBs, ou seja, parcelas em torno de 17 folhas são adequadas para a determinação do comprimento da folha $\mathrm{D}$ do abacaxizeiro 'Vitória'(Figura 2A).

Para o comprimento da folha D do abacaxi 'Vitória', a parcela ótima estimada foi de 1,8 unidade experimental básica pelo método da curvatura máxima. O coeficiente de determinação de $92 \%$ indica que os dados ajustaram a equação (Figura 2B).

O tamanho ótimo da parcela obtido pelo método linear de resposta a platô foi de 16,5 folhas, sendo a parcela estimada para a determinação da massa da folha D do abacaxizeiro. O coeficiente de determinação apresentado foi de 83\% (Figura 2C).

Observa-se, na Figura 2D, que o tamanho ótimo da parcela para a massa da folha $\mathrm{D}$ do abacaxizeiro 'Vitória' foi de 1,4 unidade básica experimental, obtido através da substituição dos valores de A e B na equação descrita na metodologia, pelo método da curvatura máxima. Houve bom ajuste dos dados à equação descrita no gráfico, com 
coeficiente de determinação de $88 \%$.

Para a avaliação do teor de nitrogênio na folha $\mathrm{D}$, foi encontrada uma parcela ótima estimada pelo modelo linear de platô de 10,5 UEBs. O coeficiente de determinação foi de $87 \%$, indicando ajuste adequado dos dados à equação (Figura $3 \mathrm{~A}$ ).

Através da substituição dos valores de A e $B$ da equação descrita na Figura $3 B$, encontrou-se o valor estimado da parcela ótima para a avaliação do teor de nitrogênio na folha $\mathrm{D}$ do abacaxizeiro 'Vitória', de 3 unidades experimentais básicas, pelo método da curvatura máxima. O coeficiente de determinação de $91 \%$ indica que houve ajuste dos dados à equação.

Para a avaliação do teor de fósforo na folha, foi encontrada uma parcela ótima estimada pelo modelo linear de platô de 10,5 UEBs. Houve ajuste dos dados à equação, indicado pelo coeficiente de determinação de 88\% (Figura 3C).

O tamanho ótimo da parcela para a avaliação do teor de fósforo na folha foi estimado através da substituição dos valores de A e B na equação, obtendo um tamanho ótimo de 4,8 unidades experimentais básicas, ou seja, em torno de 5 folhas representa a parcela ótima para esta característica, pelo método da curvatura máxima. O coeficiente de determinação de $90 \%$ indica que houve bom ajuste dos dados à equação (Figura 3D).

Para a avaliação do teor de potássio na folha, foi encontrada uma parcela ótima pelo modelo linear de platô de 10,5 UEBs, apresentando coeficiente de determinação de $87 \%$ (Figura 3E).

Observa-se, na Figura 3F, que o tamanho ótimo da parcela para a avaliação do teor de potássio na folha do abacaxizeiro 'Vitória' foi de 4,5 unidades básicas experimentais, obtido através da substituição dos valores de A e B na equação descrita na metodologia. Houve bom ajuste dos dados à equação descrita no gráfico, com coeficiente de determinação de $94 \%$.

\section{DISCUSSÃO}

O ajuste do modelo linear em resposta a platô, em todos os casos, foi considerado bom, com $\mathrm{R}^{2}$ que variou entre $81 \%$ e $88 \%$. O platô foi alcançado para um valor de $\mathrm{CV}(\mathrm{X})$ inferior a $15 \%$, exceto para os teores de $\mathrm{N}, \mathrm{P}$ e $\mathrm{K}$, e de massa da folha $\mathrm{D}$, em que o $\mathrm{CV}(\mathrm{X})$ no platô foi de $17,8 \%, 29,1 \%, 27,7 \%$ e $18,5 \%$, respectivamente. Paranaíba et al. (2009b) obtiveram resultados similares utilizando o modelo segmentado com platô, com ajuste considerado bom, apresentando $R^{2}$ que variaram entre $82,2 \%$ e $97,5 \%$ para variedades de trigo. Em quase todos os casos, o platô foi alcançado para um valor de $\mathrm{CV}(\mathrm{X})$ inferior a $10 \%$, exceto para a variedade Aliança, em que o $\mathrm{CV}(\mathrm{X})$ no platô foi de $16,23 \%$.

O tamanho ótimo encontrado pelo método de platô está de acordo com o utilizado em diversas pesquisas (SILVA et al., 2012; SILVA et al., 2009). Entretanto, alguns autores utilizaram parcelas menores: Martins et al. (2012), três infrutescências de abacaxi por parcela, Coelho et al. (2007) utilizaram cinco infrutescências por parcela.

Entretanto, como o uso do método de platô para tamanho ótimo de parcelas é recente, poucos trabalhos foram encontrados evidenciando sua aplicação para a obtenção do tamanho ótimo da parcela.

Nesta pesquisa, os valores de tamanho da parcela pelo método da curvatura máxima (MCM) variaram de 1,4 a 4,8 unidades básicas experimentais (UEB). Os valores estimados por este método foram menores quando comparados ao modelo linear de resposta a platô. Paranaíba et al. (2009b), em ensaio com arroz, encontraram tamanho da parcela de 1,7 UEB; para ensaios com trigo, os valores variaram de 2,08 a 3,42 UEB e, para ensaios com mandioca, variaram de 5,35 a 6,16 UEB. Os mesmos autores observaram que o método da curvatura máxima apresentou valores inferiores ao do método do modelo linear de platô, resultados semelhantes aos obtidos nesta pesquisa.

O modelo linear em resposta a platô permite a comparação de combinações alternativas de retas e platôs, e escolhe, como melhor opção de ajustamento, a combinação que tenha a menor soma de quadrados dos desvios. Este método tem sido utilizado em várias áreas e com diferentes propósitos.

De acordo com Silva et al. (2003), o valor da abscissa no ponto de máxima curvatura deve ser interpretado como o limite mínimo de tamanho de parcela e não como tamanho ótimo. Apesar do ajuste ao modelo, o valor apresentado neste método subestima o ótimo, resultando em um limite inferior para o valor de tamanho da parcela ótimo. Entretanto, Viana et al. (2005), apesar de encontrarem estimativas de tamanhos menores pelo método da curvatura máxima, afirmam que este foi o mais adequado.

$\mathrm{Na}$ prática, o uso do modelo linear de resposta a platô permite determinar um tamanho ideal da parcela a ser utilizada na avaliação para diversas variáveis, utilizando a quantidade adequada de unidades experimentais que represente a variabilidade dos dados, de forma que o coeficiente de variação seja o menor possível. Desta forma, poderão ser evitados experimentos com quantidade excessiva ou deficiente de parcelas, diminuindo-se custos e com resultados confiáveis. 

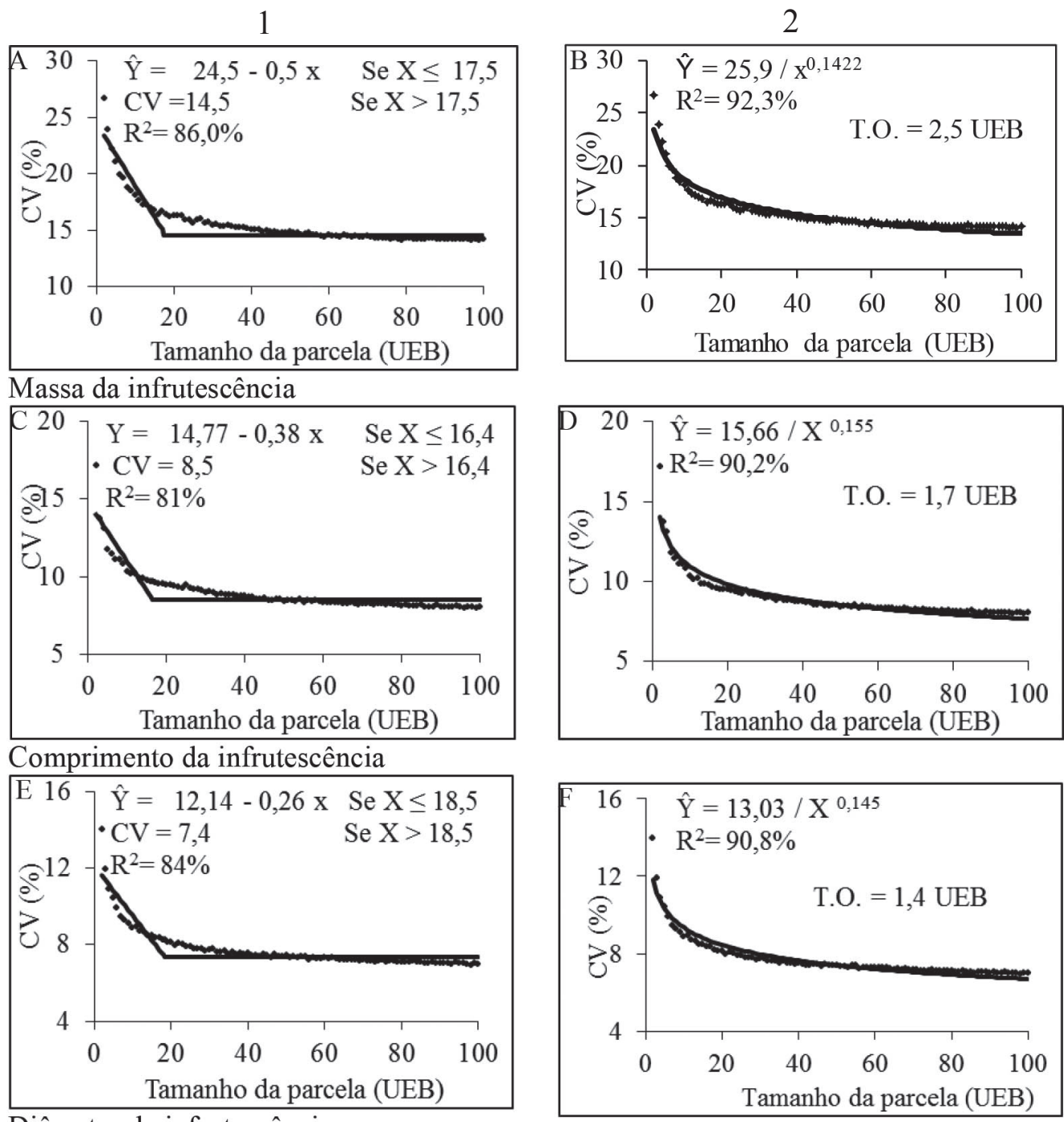

Diâmetro da infrutescência

FIGURA 1- Relação entre coeficiente de variação e tamanho da parcela pelo método Linear de Resposta a Platô (1) e pelo método da curvatura máxima (2), para massa, comprimento e diâmetro da infrutescência do abacaxizeiro 'Vitória'. T.O.= tamanho ótimo da parcela. 
1

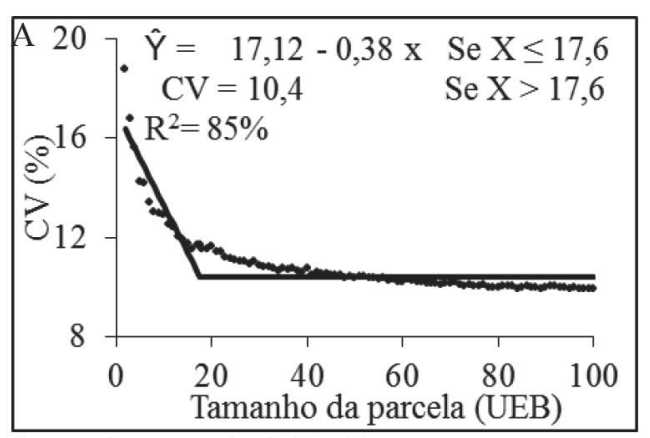

Comprimento da folha D

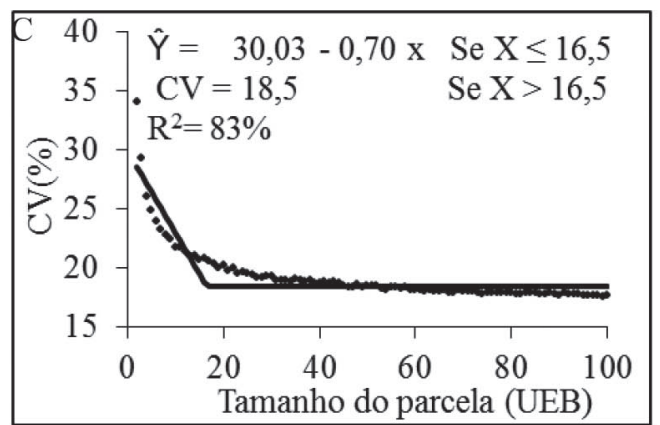

Massa da folha D
2
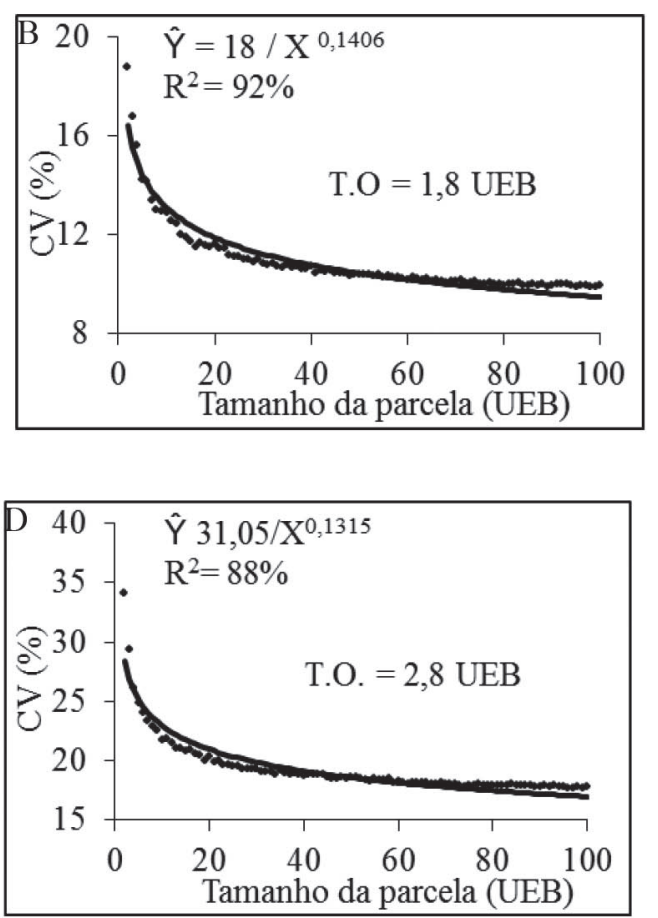

FIGURA 2 - Relação entre coeficiente de variação e tamanho da parcela pelo método Linear de Resposta a Platô (1) e pelo método da curvatura máxima (2), para comprimento e massa da folha D do abacaxizeiro 'Vitória'. T.O. = tamanho ótimo da parcela. 
1

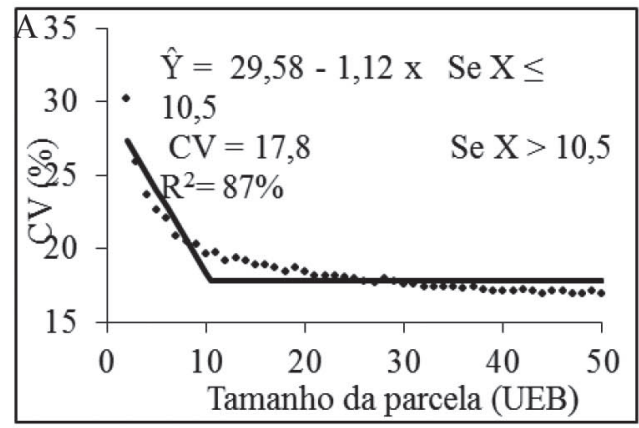

Teor de N na folha D

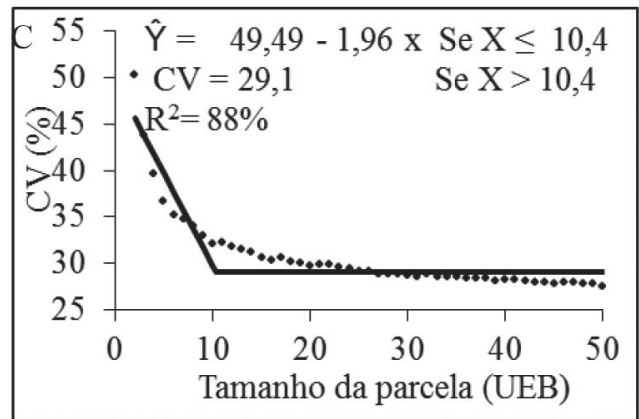

Teor de $\mathrm{P}$ na folha $\mathrm{D}$

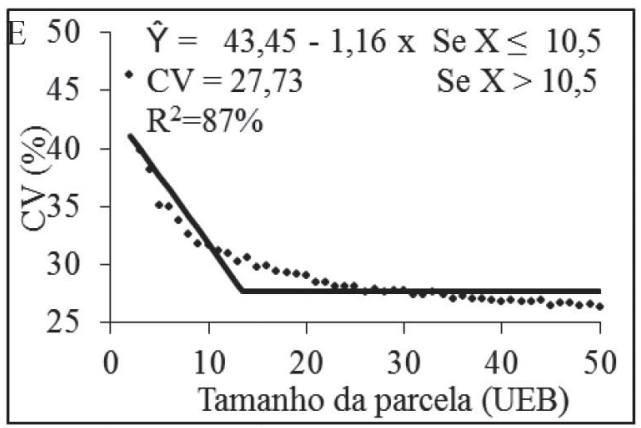

Teor de $\mathrm{K}$ na folha $\mathrm{D}$

\section{2}
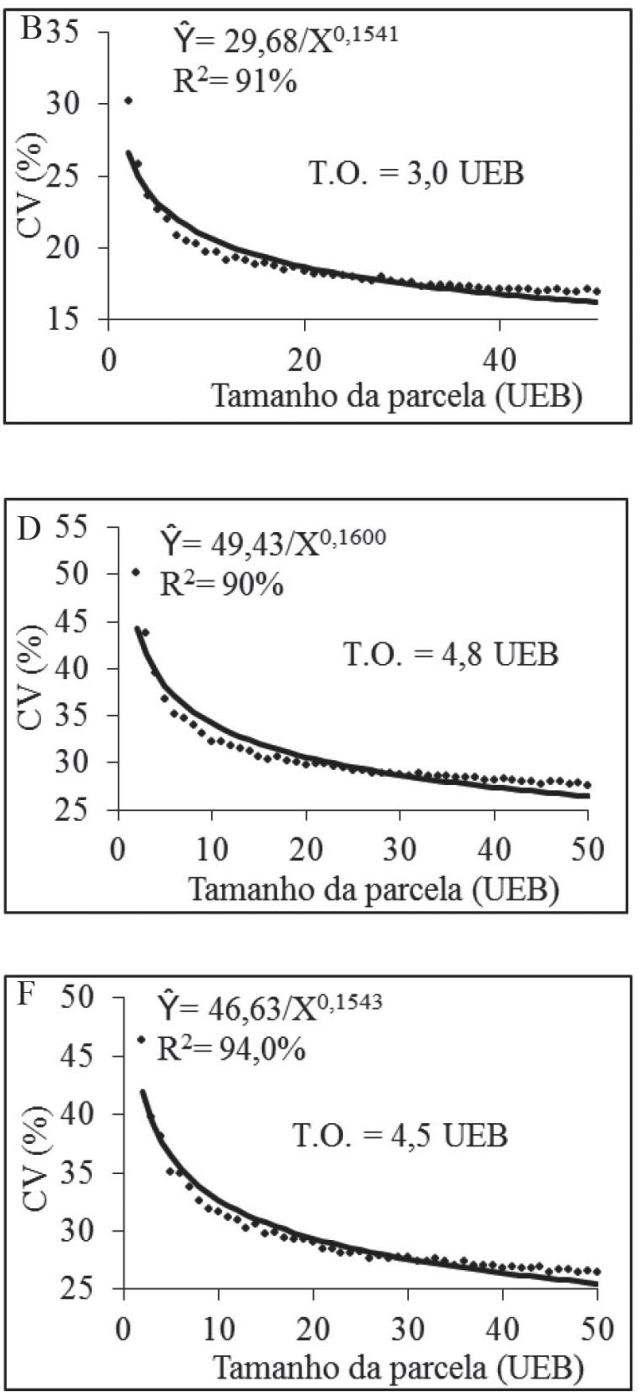

FIGURA 3 - Relação entre coeficiente de variação e tamanho da parcela pelo método Linear de Resposta a Platô (1) e pelo método da curvatura máxima (2), teores de macronutrientes na folha D do abacaxizeiro 'Vitória'. T.O.= tamanho ótimo da parcela.

\section{CONCLUSÃO}

O tamanho ótimo da parcela para a avaliação dos frutos e folhas de abacaxizeiro 'Vitória' é de 15 a 20 unidades experimentais e, para a avaliação dos teores de N, P e K, é de 10 unidades experimentais pelo método do modelo linear de resposta a platô.

O tamanho ótimo da parcela para a avaliação dos frutos e folhas é de 1,7 a 2,8 unidades experimentais e para avaliação dos teores de N, P e $\mathrm{K}$ é 3 a 5 unidades experimentais pelo método da curvatura máxima.
O método do modelo linear de resposta a platô estima valores de tamanho ótimo da parcela próximos do utilizado na prática, enquanto o método da curvatura máxima subestima os valores de tamanho da parcela, sendo estimados valores inaplicáveis na prática. 


\section{AGRADECIMENTOS}

BNB e Capes.

\section{REFERÊNCIAS}

CARGNELUTTI FILHO, A.; TOEBE, M.; BURIN, C.; CASAROTTO, G.; LÚCIO, A. D. Métodos de estimativa do tamanho ótimo de parcelas experimentais de híbridos de milho simples, triplo e duplo. Ciência Rural, Santa Maria v.41, n.9, p.15091516, 2011.

COELHO, R.I.; LOPES, J.C.; CARVALHO, A .J.C.;AMARAL, J.A.T.; MATTA, F.P. Estado nutricional e características de crescimento do abacaxizeiro Jupi cultivado em Latossolo Amarelo distrófico em função da adubação com NPK. Ciência eAgrotecnologia, Lavras, v. 31, n. 6, p. 1696-1701, 2007.

LESSMAN, K. J.; ATKINS, R. E. Optimum plot size and relative efficiency of lattice designs for grain sorghum yield tests. Crop Science, Madison, v. 3, n. 5 , p. 477-481. 1963.

MAMMEN, E.; NANDI, S. Bootstrap and resampling. In: GENTLE, J.E. et al. (Ed.). Handbook of computational statistics, springer handbooks of computational statistics. Heidelberg: Springer-Verlag, 2012. cap. 17, p. 499-527

MARTINS, L.P.; SILVA, S. M.; SILVA, A.P.; CUNHA, G. A .P.; MENDONÇA, R. M. U.; VILAR, L. C.; MASCENA, J.; LACERDA, J. T. Conservação pós-colheita de abacaxi 'Pérola' produzido em sistemas convencional e integrado. Revista Brasileira de Fruticultura, Jaboticabal, v.34, n.3, p.695-703, 2012.

OLIVEIRA, E.F.; CARVALHO, R.A; LACERDA, J.T.; CHOAIRY, S.A.; BARREIRO NETO, M. Abacaxi: sistema de cultivo para o tabuleiro paraibano. João Pessoa: EMEPA, 2002. 38p.

PARANAÍBA, P.F. et al. Tamanho ótimo de parcelas experimentais: proposição de métodos de estimação. Revista Brasileira de Biometria, Jaboticabal, v.27, n.2, p.255-268, 2009a.
RODRIGUES, A. A.; MENDONÇA, R. M. N.; SILVA, A. P.; SILVA, S. M. Nutrição mineral e produção de abacaxizeiro 'Pérola', em função das relações $\mathrm{K} / \mathrm{N}$ na adubação. Revista Brasileira de Fruticultura, Jaboticabal, v.35, n.2, p. 625-633, 2013.

SAS. SAS/STAT 9.3 user's guide. Cary, 2011. 8621 p.

SILVA, A. L. P. et al. Resposta do abacaxizeiro 'Vitória' a doses de nitrogênio em solos de tabuleiros costeiros da Paraíba. Revista Brasileira de Ciência do Solo, Viçosa, MG, v.36, n.2, p. 447-456, 2012.

SILVA, A. P.; ALVAREZ V., V. H.; SOUZA, A. P.; NEVES, J. C. L.; NOVAIS, R. F.; DANTAS, J. P. Sistema de recomendação de fertilizantes e corretivos para a cultura do abacaxi-Fertcalc-Abacaxi. Revista Brasileira de Ciência do Solo, Viçosa, MG, v.33, n.5, p.1269-1280, 2009.

SILVA, R. L.; XAVIER, A.; LEITE, H. G.; PIRES, I. E. Determinação do tamanho ótimo da parcela experimental pelos métodos da máxima curvatura modificada, do coeficiente de correlação intraclasse e da análise visual em testes clonais de eucalipto. Revista Árvore, Viçosa, MG, v.27 n.5, p.669-676, 2003. 